\title{
Developing Science Education and Outreach Partnerships at Research Institutions
}

\author{
By K. L. Dow \\ Harvard-Smithsonian Center for Astrophysics, Cambridge, MA, USA \\ Harvard Graduate School of Education, Cambridge, MA , USA
}

\section{Introduction}

Like many research institutions, the Harvard-Smithsonian Center for Astrophysics $\dagger$ (CfA), has been actively engaged in education and public outreach activities for many years. The Harvard University Department of Astronomy, the formal higher education arm of the CfA, offers an undergraduate concentration and a doctoral program. In our Science Education Department, educational researchers manage ten programs that address the needs of teachers and students (K-12 and college), through advanced technology, teacher enhancement programs, and the development of curriculum materials. The Editorial and Public Affairs Department offers several public lecture series, recorded sky information, children's nights, and runs the Whipple Observatory Visitors Center in Amado, AZ. In this environment of successful programs, the High Energy Astrophysics (HEA) division, one of seven research divisions at the CfA, has initiated, or partnered with other institutions, development of several new education and outreach programs. Some of these programs involve partnerships with the education community, but all of them have been initiated by and involve scientists.

Astronomical research in the HEA division is mainly focused on $\mathrm{x}$-ray astronomy and the development of advanced $x$-ray instrumentation. Historically, involvement in education and outreach programs, including presenting public talks, school talks, the development of slides sets, and the publication of popular articles, has been informal. With management support, however, this long-lived tradition of informal education and outreach recently has coalesced into several formal programs that target three specific groups: college students, K-12 students and teachers, and the general public. This paper describes the projects which have been developed in the last three years, including the SAO Summer Intern Program, Astronomy in Motion, Live from the Smithsonian, Science Information Infrastructure, An International Exploration of the Universe, Everyday Classroom Tools, as well as some of the lessons we have learned about developing education and outreach programs in a research setting.

All of these formal programs complement the ongoing activities of individual researchers and are but a part of an overall effort in the HEA division to make our expertise, our facilities, and our excitement about science more accessible to teachers, students, and the general public. More information about these and other programs is available from the author or from the HEA division education and outreach homepage: http://heawww.harvard.edu/scied/.

† The Smithsonian Astrophysical Observatory (SAO) is a research bureau of the Smithsonian Institution. Research at the Harvard University Department of Astronomy is carried out at the Harvard College Observatory ( $\mathrm{HCO}$ ). Together, the two institutions comprise the Harvard-Smithsonian Center for Astrophysics. 


\section{Outreach Programs}

\subsection{Programs for College Students and Teachers}

Smithsonian Astrophysical Observatory Summer Intern Program

The National Science Foundation (NSF) sponsored Research Experiences for Undergraduates (REU) program at the Smithsonian Astrophysical Observatory (SAO) in Cambridge, MA, provides talented undergraduates with an opportunity to actively participate in an astronomical research project. The primary goals of the SAO Summer Intern Program are to expose college students to an actual research environment in order to help them focus their career goals, to encourage their development as physical scientists, and to empower students to become full participants in a scientific and technological society. Students spend 10 weeks at the SAO beginning the second week of June and are recruited from US colleges and universities that offer programs in the physical sciences.

While this program is run by the HEA division, students may work with a senior scientist from any research division. Students also are assigned to a graduate student or post-doctoral fellow "mentor" during their appointment. We believe that the experience of assisting a senior scientist in the supervision of a participant in the program may encourage these "mentors" to work with undergraduates later in their careers.

Students engage in a research program in a variety of areas, including observational and theoretical astronomy, extragalactic and galactic astronomy, interstellar medium and star formation, laboratory astrophysics, supernovae and supernova remnants, and planetary science. While they spend the majority of their time working on a research project, regular lectures and meetings also are held throughout the summer. These gatherings are designed to further expose students to the wide breadth of modern astrophysical research. Other program activities include local field trips, a colloquia series, discussion evenings, and the opportunity to present research results at a professional meeting. The program concludes with an "Intern Symposium" where the participants present the results of their work. The overall structure of the program is designed to provide students with challenges of increasing difficulty. We feel that as students master more difficult tasks, they achieve greater self-reliance as researchers. The SAO Summer Intern Program is one of several similar programs offered at research institutions across the US.

Project JOVE

As a mentor institution for NASA's Project JOVE, SAO offers research opportunities for faculty members that cover a wide range of possible astrophysics topics. The primary goal of Project JOVE is to establish three year joint venture partnerships between NASA and institutions of higher education which have had little or no involvement in the Nation's space program. Four faculty members from three colleges have recently participated in Project JOVE at SAO in the HEA division. The experience includes a 10 week research internship during the first summer. Current areas of interest for some HEA staff members particularly interested in Project JOVE are outlined at the following url: http://hea-www.harvard.edu/scied/jove/jove_sao.html.

\subsection{Programs for K-12 Students and Teachers}

\section{Science Information Infrastructure}

The Science Information Infrastructure (SII) is a consortium of science centers and museums linked together to bring current research topics to the public. The HEA division at SAO, in partnership with the Center for EUV Astrophysics, is working to create a network of on-line resources created by teams of teachers, science museum personnel, scientists and technical staff. Thirteen curriculum modules have been created so far and can be accessed from World Wide Web sites at the Exploratorium, the Lawrence Hall 
of Science, the National Air and Space Museum, and the Science Museum of Virginia. All of the modules can be found on the Center for EUV Astrophysics SII homepage (http://www.cea.berkeley.edu/Education/sii/sii_sii.html). The resources being created are intended for use by anyone, but especially in the classroom setting as well as for exploratory learning.

In the $S I I$ model, the small, local focus teams of teachers and individuals from the science museums and partner research institutions create on-line curriculum for science and math classes based on NASA data and related information and networked science research services. The life cycle of the materials and on-line tools involves testing in the classroom, evaluation, modification and revision and further testing in different environments. The $S I I$ is intended to build a sustainable framework for this process and accommodate new and experimental activities that use networked technology in innovative ways. SII is a three year program funded by NASA's Public Use of Remote Sensing Data Program.

An International Exploration of the Universe

Two Russian and two Massachusetts High Schools are working with an SAO scientist in Cambridge, MA and an Institute for Space Research scientist in Moscow to study the multi- wavelength aspects of astronomy. As part of the theme of multi-wavelength astronomy, the scientists introduce the "missing mass"question through the analysis of clusters of galaxies using NASA data, study galaxy redshifts and the expanding universe, and utilize public-access robotic telescopes. Astronomical observing using small telescopes complements the computer- based activities to view "ideal"multi-wavelength objects such as the Orion Nebula, the optical counterpart to the probable black hole Cygnus X-1, globular clusters, open clusters, and M31. Observing nights are also offered to help forge links between the communities and the schools. This project fosters a wide range of communications between different school systems and promotes international understanding. An International Exploration of the Universe is funded by a grant from the NASA Initiative to Develop Education through Astronomy program.

City Stars: A Teacher Workshop on Astronomy

In collaboration with Charles Hayden Planetarium staff, SAO scientists developed and offer two annual astronomy workshops, City Stars, for Boston area middle and high school teachers at the Boston Museum of Science. The workshops cover basic astronomy concepts and demonstrations of inexpensive hands-on astronomy activities. Participants receive a teacher's packet consisting of a workbook with descriptive guidesheets for each activity, a cassette tape with astronomy songs, solar system slide set, spectroscope, disposable outdoor camera, sundial template, star finder template, Styrofoam ball and pencil, Saturn poster, and Museum of Science brochures. Workshop participants complete a formal evaluation of the in-class experience. City Stars is funded by a grant from the NASA Initiative to Develop Education through Astronomy program.

Everyday Classroom Tools

Everyday Classroom Tools is a three year program funded by NASA's Public Use of Remote Sensing Data Program. HEA division scientists and programmers are working with two Massachusetts elementary schools to develop an inquiry-based astronomy curriculum for elementary school students. The use of technology to learn about the world is another major goal of the project. Macintosh computers with CD-ROM capabilities and direct access to the Internet connect all the participating teachers and permits communication among the teachers and the program personnel. Everyday Classroom Tools staff also have developed a series of hands-on astronomy activities called "Eyes on the Sky, Feet on the Ground,"partially funded by a Smithsonian Outreach grant. These materials are available on-line at http://hea-www.harvard.edu/ECT/the_book/index.html. 


\subsection{Programs for the General Public}

Astronomy in Motion

English and Spanish posters on "The Sun" and "Jupiter" were displayed on the Massachusetts Bay Transit Authority (MBTA) subway in late 1995 and early 1996. These posters use eye-catching graphics to heighten interest and appreciation of astronomy among the general public. The posters were distributed to Boston area schools, along with introductory material on the Sun and Jupiter, a list of related books, World Wide Web sites, and classroom activities. We are presently working to expand the project to also include transit systems in New York City, San Francisco, and Washington, DC. The Astronomy in Motion pilot project was funded by the National Aeronautics and Space Administration.

Live from the Smithsonian

Science museums around the country often enlist astronomers to occupy an "Ask-anAstronomer"booth on Astronomy Day. While these booths are tremendously popular with museurn visitors of all ages, they are short lived. Recent developments in video conferencing hardware and software now provide the opportunity to enhance this activity, and to involve greater numbers of astronomers.

In the past, teleconferencing with scientists through satellite downlinks has proven immensely popular with the museum-going public. At the Boston Museum of Science, for example, students and teachers followed oceanographer Bob Ballard and colleagues on a marine archaeological expedition, and chatted with Russian cosmonauts aboard Mir. Live from the Smithsonian will expand the capabilities of teleconferencing by encouraging the kind of in-depth, iterative discussion that leads to deeper understanding.

As a test of the application of video conferencing in a typical museum environment, we will place a video conference kiosk on the floor of the "Stars" Gallery at the National Air and Space Museum (NASM) that will provide Museum visitors with the opportunity to "Ask-a- Smithsonian-Astrophysical-Observatory-Astronomer" questions during regularly scheduled sessions. To prepare NASM visitors to talk with astronomers, the kiosk will also be set up as a touch-screen to provide the visitor with an introduction to the astronomical research presently conducted at the Smithsonian Institution. Screens will be available to describe the Smithsonian Astrophysical Observatory programs, where the Observatory is located, who will be available that week for discussions, and what their specialties are. The kiosk will also describe representative research areas - the mysteries - along with "frequently asked questions" from the public.

While a few other science centers and museums (Exploratorium, Oregon Museum of Science and Technology, Ithaca Science Center), currently have video conferencing capabilities, this will be the first time that this new technology will be incorporated into an exhibit. It will be a test for considering the use of video conferencing and remote maintenance of updatable information in Smithsonian galleries that deal with contemporary issues in science.

The main educational goals of this project are: encourage general public and K-12 student interest in astronomy, involve at least 60 astronomers in a three month public outreach activity, show that astronomers come from many backgrounds, promote greater awareness of the research side of the Smithsonian Institution and its activities beyond "The Mall," and to form a partnership (between astronomers, educational researchers, exhibit designers, curators, teachers, students, and the general public) that may lead to future collaborations. The main museum-based goals of this project are: explore efficient and easily updatable means of presenting contemporary information about astronomy and space research to the public in a major and very demanding museum environment, 
and to explore ways to promote greater contact between the research side of the Smithsonian and the Smithsonian's patrons. The Live from the Smithsonian project will open in the Stars Gallery in the Spring of 1997.

\section{Conclusion}

The marriage of science and education at the Harvard-Smithsonian Center for Astrophysics is similar to all such unions. Each partner is distinct and brings strengths, weaknesses, and idiosyncrasies to the relationship. Further, the partners need not lose their individuality by working together and may even produce some interesting offspring.

Recall the Fred Astaire and Ginger Rogers film Shall We Dance. In this film, think of Fred as science and Ginger as education. Fred is a famous ballet dancer who wishes he had the freedom to be a tap dancer. Ginger is a famous tap dancer who wishes she had the respect that ballet dancers command. Fred and Ginger only know each other by reputation, but Fred vows to marry Ginger before he even meets her. Then through a series of events, familiar to any fan of 1930's movies, it is incorrectly announced in the paper that Fred and Ginger are already married. In the end, however, love conquers all and they do marry and live happily ever after.

It is my hope that science and education, like partners in any marriage, will come to see that the longer they are together, the more they realize how much they have in common. The marriage of science and education will undoubtedly lead to the birth of new ideas, new approaches to developing and disseminating curriculum, and new methods of conveying the excitement of science to students and the general public, in ways that we cannot foresee today. Finally, those who think that Fred was a genius, and that this somehow diminishes Ginger's contribution to their films, should recall that Ginger did everything Fred did, only backward and in high heels. 